\title{
Kaempferol suppresses cell metastasis via inhibition of the ERK-p38-JNK and AP-1 signaling pathways in U-2 OS human osteosarcoma cells
}

\author{
HUI-JYE CHEN ${ }^{1}$, CHUNG-MING LIN ${ }^{5}$, CHAO-YING LEE ${ }^{2}$, NAI-CHEN SHIH ${ }^{3}$, SHU-FEN PENG ${ }^{4}$, \\ MINORU TSUZUKI ${ }^{6}$, SAKAE AMAGAYA ${ }^{7}$, WEN-WEN HUANG ${ }^{4}$ and JAI-SING YANG ${ }^{3}$ \\ ${ }^{1}$ Graduate Institute of Molecular Systems Biomedicine, ${ }^{2}$ School of Pharmacy, Departments of ${ }^{3}$ Pharmacology \\ and ${ }^{4}$ Biological Science and Technology, China Medical University, Taichung 40402; ${ }^{5}$ Department of \\ Biotechnology, Ming Chuan University, Taoyuan 333, Taiwan, R.O.C.; Departments of ${ }^{6}$ Biochemistry and \\ ${ }^{7}$ Kampo Pharmaceutical Sciences, Nihon Pharmaceutical University, Saitama 362-0806, Japan
}

Received February 26, 2013; Accepted April 22, 2013

DOI: 10.3892/or.2013.2490

\begin{abstract}
Kaempferol is a natural flavonoid that possesses anti-proliferative and apoptosis-inducing activities in several cancer cell lines. In the present study, we investigated the anti-metastatic activity of kaempferol and its molecular mechanism(s) of action in human osteosarcoma cells. Kaempferol displayed inhibitory effects on the invasion and adhesion of U-2 osteosarcoma (OS) cells in a concentrationdependent manner by Matrigel Transwell assay and cell adhesion assay. Kaempferol also inhibited the migration of U-2 OS cells in a concentration-dependent manner at different treatment time points by wound-healing assay. Additional experiments showed that kaempferol treatment reduced the enzymatic activities and protein levels of matrix metalloproteinase (MMP)-2, MMP-9 and urokinase plasminogen activator (uPA) by gelatin and casein-plasminogen zymography assays and western blot analyses. Kaempferol also downregulated the mRNA levels of MMP-2 and MMP-9 by quantitative PCR analyses. Furthermore, kaempferol was able to reduce the protein phosphorylation of ERK, p38 and JNK by western blotting. By electrophoretic mobility-shift assay (EMSA), we demonstrated that kaempferol decreased the DNA binding activity of AP-1, an action likely to result in the reduced expression of MMP-2, MMP-9 and UPA. Collectively, our data showed that kaempferol attenuated the MAPK signaling pathways including ERK, JNK and p38 and resulted in the decreased DNA binding ability of AP-1, and hence, the downregulation in the expression and enzymatic activities of MMP-2, MMP-9 and uPA, contributing to the inhibition of
\end{abstract}

Correspondence to: Dr Jai-Sing Yang, Department of Pharmacology, China Medical University, 91 Hsueh-Shih Road, Taichung 40402, Taiwan, R.O.C.

E-mail: jaising@mail.cmu.edu.tw

Key words: kaempferol, metastasis, ERK, p38, JNK, AP-1, U-2 osteosarcoma cells metastasis of U-2 OS cells. Our results suggest a potential role of kaempferol in the therapy of tumor metastasis of OS.

\section{Introduction}

Osteosarcoma (OS) is the most common primary solid malignancy of bone which originates from the malignant transformation of mesenchymal cells that are destined to develop into osteoid and bone (1). This disease primarily afflicts children and adolescents and is responsible for approximately $20 \%$ of all types of bone cancer $(2,3)$. In addition, OS is the second highest cause of cancer-related mortality in these age groups, mainly due to the fatal metastasis to the lung (4). Clinical studies have shown that approximately $80 \%$ of OS tumors may finally gain metastatic potential (5), while the remaining $20 \%$ of OS tumors stay regional and never metastasize, indicating an inherent metastatic potential exists in OS tumors. Thus, OS is a highly metastatic tumor, and pulmonary metastases are the most common cause of mortality. Through combined treatment of surgery with chemotherapy, and sometimes radiotherapy, the average 5-year disease-free survival rate for OS patients without metastatic disease is $60-70 \%$, while the 5 -year survival rate of patients with metastatic disease is as low as $10-20 \%$ (6). Furthermore, OS patients with metastases have a poor prognosis and their long-term survival rates are approximately $10-30 \%$ (7). Therefore, there is an urgent need to develop novel drugs to treat OS patients with metastasis.

Flavonoids are plant secondary metabolites that play a role in the defense against microorganisms or pests (8) and are part of oxidative stress protection pathways (9). Flavonoids can be divided into several subgroups including flavones, flavonols, flavanones, flavanols, flavanonols, isoflavones, and anthocyanidins (10). Studies have shown that flavonoids exhibit numerous biological and pharmacological properties (11), such as anti-viral (12), anticancer (13), anti-oxidative (14), anti-inflammatory (15), anti-allergic (16), anti-microbial (17), lipolytic (18), and hepatoprotective activities (19), as well as the prevention of cardiovascular diseases (20). Kaempferol, 3, 4', 5, 
7-tetrahydroxyflavone, a natural flavonoid, has been isolated from various plant sources including caper, kale cress, broccoli, tomatoes, hop, red grapes, grapefruit, strawberries, apples and Ginkgo biloba (21). Kaempferol can also be found as an ingredient of honey, green and black tea (21-26). Kaempferol and its derivatives are known for their anti-oxidant, antiinflammatory, anti-microbial, anti-diabetic, neuroprotective, and cardioprotective activities (27). Furthermore, it has been reported that kaempferol has anti-proliferation activity and can induce apoptosis in several human cancer cell lines, such as non-small cell lung cancer (28), esophageal cancer (29), leukemia (30), oral cavity cancer (31), prostate cancer (32), colon cancer (33) and OS (34).

It is well known that natural phenolic compounds from plants are able to prevent cancer metastasis (35) and, among them, flavonoids are effective natural agents with anti-invasive and/or anti-metastatic activities against various types of cancer such as brain, breast, lung, colon, cervical, prostate cancer and melanoma (10). As a member of flavonoids, kaempferol displayed anti-invasive activity by reducing MMP-3 activity in MDA-MB-231 human invasive breast carcinoma cells (36). Kaempferol can also suppress the HGF-induced phosphorylation of Met and Akt, leading to the inhibition of cell migration of medulloblastoma DAOY cells (37). In addition, kaempferol is able to repress the TPA-induced invasion and migration by prohibiting the PKC $\alpha / E R K / N F-\kappa B$ signaling pathway in GBM8401 glioblastoma cells (38). However, the anti-metastatic effects of kaempferol on OS remain unclear. In this study, we presented evidence to show that kaempferol was able to inhibit invasion, migration and adhesion of U-2 OS cells. Further evidence indicated that kaempferol suppressed the ERK, p38, JNK as well as the AP-1 signaling pathways and thus reduced the expression and enzymatic activities of matrix metalloproteinases (MMPs) and urokinase plasminogen activator (uPA), contributing to the inhibition of OS metastasis.

\section{Materials and methods}

Chemicals and reagents. Kaempferol was purchased from Sigma-Aldrich (St. Louis, MO, USA) and solubilized in dimethyl sulfoxide (DMSO; Sigma-Aldrich). Antibodies against MMP-2, MMP-9, $\beta$-actin, uPA and GAPDH were obtained from Santa Cruz Biotechnology, Inc. (Santa Cruz, CA, USA). Antibodies against phospho-JNK (Thr183/Tyr185), phosphop38 (Thr183/Tyr185), and phospho-ERK (Thr202/Tyr204) were obtained from Cell Signaling Technology, Inc. (Danvers, MA, USA). HRP-coupled secondary antibodies such as rabbit antimouse IgG, goat anti-rabbit IgG, and donkey anti-goat IgG were obtained from Santa Cruz Biotechnology Inc. 3-(4,5-dimethyl2-thiazolyl)-2,5-diphenyl-2H-tetrazolium bromide (MTT) was purchased from Sigma-Aldrich. RPMI-1640 medium, fetal bovine serum (FBS), L-glutamine, penicillin-streptomycin and trypsin-EDTA were obtained from Gibco-BRL (Carlsbad, CA, USA). All other chemicals were obtained from Sigma-Aldrich and Merck KGaA (Darmstadt, Germany) unless otherwise indicated.

Cell culture. Human OS cell line, U-2 OS, was purchased from the Food Industry Research and Development Institute (FIRDI, Hsinchu, Taiwan) and cultured in McCoy's 5A medium, supplemented with $10 \% \mathrm{FBS}, 100 \mathrm{U} / \mathrm{ml}$ penicillin, $100 \mu \mathrm{g} / \mathrm{ml}$ streptomycin and $2 \mathrm{mM}$ glutamine (all from Gibco-BRL), and incubated at $37^{\circ} \mathrm{C}$ in a humidified chamber with $5 \% \mathrm{CO}_{2}$ (39).

Cell invasion assay. The membrane of each Transwell insert was washed with 1X PBS and coated with Matrigel $(2 \mathrm{mg} / \mathrm{ml}$, $20 \mu \mathrm{l}$; BD Matrigel ${ }^{\mathrm{TM}}$ Invasion chamber). Cells $\left(2.5 \times 10^{4}\right)$ were seeded into the chamber of the insert and incubated with $0.5 \mathrm{ml}$ of complete McCoy's 5A medium in each Transwell. Cells were treated with various concentrations of kaempferol $(0,25,50$ and $100 \mu \mathrm{M})$ for $48 \mathrm{~h}$ and cells inside the chamber were removed. Invaded cells were fixed with $4 \%$ formaldehyde in PBS and stained with $0.1 \%$ of hematoxylin, photographed and the number of invaded cells was counted and the relative cell invasion was calculated $(40,41)$.

Cell adhesion assay. We used cell-matrix adhesion assay to determine cell adhesion. U-2 OS cells $\left(2.5 \times 10^{4} / \mathrm{ml}\right)$ were treated with various concentrations of kaempferol $(0,25,50$ and $100 \mu \mathrm{M})$ for $48 \mathrm{~h}$, and then seeded for $2 \mathrm{~h}$ onto 24 -well plates that were pre-coated with $150 \mu \mathrm{l}$ type I collagen $(10 \mu \mathrm{g} / \mathrm{ml})$ (EMD Millipore). Subsequently, non-adherent cells were removed and adherent cells were washed with PBS and fixed in $70 \%$ ethanol for $15 \mathrm{~min}$. Fixed cells were stained with $0.2 \%$ crystal violet for $10 \mathrm{~min}$, and then lysed in $0.2 \%$ Triton X-100 for $30 \mathrm{~min}$. The absorbance of the lysed solution was measured at $550 \mathrm{~nm}$ by a microplate reader and used to calculate the relative cell viability. Each treatment was in duplicate, and 3 independent experiments were performed $(40,41)$.

Cell migration assay. U-2 OS cells $\left(2.5 \times 10^{5}\right)$ were seeded into 6-well plates and grown to $90 \%$ confluency. Cells were then scratched with a tip and treated with various concentrations of kaempferol $(0,25,50$ and $100 \mu \mathrm{M})$ in McCoy's 5A serum-free medium for 24 and $48 \mathrm{~h}$. The cells were photographed and cells that migrated into the denuded zone were counted to calculate the relative cell migration. All treatments were in duplicate and three independent experiments were performed $(40,41)$.

Gelatin zymography analysis. U-2 OS cells $\left(1 \times 10^{6}\right)$ were seeded into 6-well plates for $4 \mathrm{~h}$ and treated with various concentrations of kaempferol $(0,25,50,75$ and $100 \mu \mathrm{M})$ in serum-free McCoy's 5A medium for an additional $24 \mathrm{~h}$. Culture medium was spun at $1,000 \mathrm{x} \mathrm{g}$ for $10 \mathrm{~min}$ at $4^{\circ} \mathrm{C}$ and supernatant was collected. Then, $5 \mu \mathrm{g}$ of total protein was mixed with $2 \mathrm{X}$ sample buffer $(0.125 \mathrm{M}$ Tris- $\mathrm{HCl}, 4 \%$ SDS, $20 \%$ glycerol, $0.01 \%$ bromophenol blue) and resolved in an $8 \%$ SDS-polyacrylamide gel containing $1 \%$ gelatin. The gel was incubated with $2.5 \%$ Triton X-100 for $30 \mathrm{~min}$, and incubated in zymogen developing buffer $(50 \mathrm{mM}$ Tris, $\mathrm{pH}$ 7.5, $200 \mathrm{mM} \mathrm{NaCl}, 5 \mathrm{mM} \mathrm{CaCl} \mathrm{Cl}_{2}, 1 \mu \mathrm{M} \mathrm{ZnCl}_{2}, 0.02 \%$ Brij35; Bio-Rad Laboratories; Hercules, CA, USA) at $37^{\circ} \mathrm{C}$ for $16-18 \mathrm{~h}$. The gel was then rinsed with water and stained with 0.5\% Coomassie Blue G-250 (0.5\% Coomassie Blue G-250, $50 \%$ methanol, and $10 \%$ acetic acid) for $3 \mathrm{~h}$, and de-stained in de-staining solution (50\% methanol and $10 \%$ acetic acid) until clear zones were visualized. The gel was scanned by a scanning digitizing system and processed by using ImageJ software (NIH) $(40,41)$. 
Casein-plasminogen zymography analysis. U-2 OS cells $\left(1 \times 10^{6}\right)$ were seeded into 6 -well plates and treated with various concentrations of kaempferol $(0,25,50,75$ and $100 \mu \mathrm{M})$ in serum-free McCoy's 5A medium for $48 \mathrm{~h}$. Protein in culture medium was collected as described above and used for assaying the uPA activity. Then, $30 \mu \mathrm{g}$ of total proteins were electrophoresed in an $8 \%$ SDS-PAGE gel containing $2 \%$ casein and $20 \mu \mathrm{g} / \mathrm{ml}$ plasminogen and zymography was analyzed as described in the gelatin zymography analysis $(40,41)$.

Preparation of whole cell and nuclear protein lysate. U-2 OS cells were treated with various concentrations of kaempferol for the indicated times, and cells were harvested for the preparation of whole cell lysate using extraction buffer containing ice-cold RIPA buffer (1\% NP-40, $50 \mathrm{mM}$ Tris-base, $0.1 \%$ SDS, $0.5 \%$ deoxycholic acid, $150 \mathrm{mM} \mathrm{NaCl}, \mathrm{pH} 7.5$ ) supplemented with the protease inhibitors including phenylmethanesulfonyl fluoride $(10 \mathrm{mg} / \mathrm{ml})$, leupeptin $(17 \mathrm{mg} / \mathrm{ml})$ and sodium orthovanadate $(10 \mathrm{mg} / \mathrm{ml})$. Cells were completely re-suspended in extraction buffer and incubated in ice for $30 \mathrm{~min}$ with occasional mixing, and cell lysates were collected by a spin at $12,000 \mathrm{x} \mathrm{g}$ for $10 \mathrm{~min}$ at $4^{\circ} \mathrm{C}$. Nuclear extracts were prepared by using the NE-PER Nuclear and Cytoplasmic Extraction kit (Thermo Scientific, Rockford, IL, USA). The obtained nuclear pellet was solubilized in nuclear extraction buffer $(1.5 \mathrm{mM}$ $\mathrm{MgCl}_{2}, 10 \mathrm{mM}$ HEPES, pH 7.9, $0.1 \mathrm{mM}$ EDTA, $0.5 \mathrm{mM}$ dithiothreitol, $0.5 \mathrm{mM}$ phenylmethanesulfonyl fluoride, $25 \%$ glycerol and $420 \mathrm{mM} \mathrm{NaCl}$ ), and incubated in ice for $20 \mathrm{~min}$, then centrifuged at $14,000 \times \mathrm{g}$ for $5 \mathrm{~min}$. The supernatant, corresponding to the soluble nuclear fraction, was collected for the electrophoretic mobility shift assay (EMSA) of AP-1. The protein concentrations were determined by using Bio-Rad Protein Assay Dye Reagent Concentrate (Bio-Rad) (41).

EMSA. U-2 OS cells were seeded at a density of $5 \times 10^{6}$ the day prior to treatment. Cells were then treated with $100 \mu \mathrm{M}$ of kaempferol for $12 \mathrm{~h}$. Soluble nuclear fraction was prepared as described above. Biotin end-labeled oligonucleotide corresponding to the consensus AP-1 binding site (5'-CGCTTGATGACTCAGCCGGAA-3') was prepared with the LightShift Chemiluminescent EMSA kit (Thermo Scientific) and used as the probe. Then, $5 \mu \mathrm{g}$ of nuclear extract was incubated with biotin end-labeled duplex DNA, electrophoresed in a $6 \%$ polyacrylamide native gel, transferred to a positive nylon membrane, UV cross-linked, and incubated with streptavidin-HRP. Signals were developed by enhanced chemiluminescence using the ECL kit from Millipore (Billerica, MA, USA) (41).

Western blotting. Whole cell lysate was prepared from treated cells as described above, electrophoresed in sodium dodecyl sulfate-polyacrylamide gel and transferred onto polyvinylidene fluoride (PVDF) membrane (Millipore). The membranes were then incubated in blocking buffer $(5 \%$ non-fat milk and $0.1 \%$ Tween-20 in Tris-buffered saline) for $1 \mathrm{~h}$ and incubated with primary antibody in $1 \%$ non-fat milk (with $0.1 \%$ Tween-20 in Tris-buffered saline) at $4^{\circ} \mathrm{C}$ overnight. Membranes were washed with $0.1 \%$ Tween-20 in Tris-buffered saline 3 times for $10 \mathrm{~min}$ before incubating with HRP-conjugated secondary antibody at room temperature for $1 \mathrm{~h}$. Protein signals were detected by enhanced chemiluminescence (ECL) (41).

Quantitative real-time PCR analyses of MMP-2 and MMP-9 genes. U-2 OS cells were treated with 0 and $100 \mu \mathrm{M}$ of kaempferol for $24 \mathrm{~h}$ and cells were collected for the isolation of total RNAs using the Qiagen RNeasy mini kit. cDNAs were obtained using the High Capacity cDNA reverse transcription kit according to the standard protocol provided by the supplier (Applied Biosystems, Foster City, CA, USA). Then, $1 \mu \mathrm{l}$ of reverse-transcribed cDNA was mixed with $2 \mathrm{X}$ SYBR-Green PCR master mix (Applied Biosystems) and $200 \mathrm{nM}$ of forward and reverse primers for the quantitative PCR according to the following conditions: $2 \mathrm{~min}$ at $50^{\circ} \mathrm{C}, 10 \mathrm{~min}$ at $95^{\circ} \mathrm{C}$, and 40 cycles of $15 \mathrm{sec}$ at $95^{\circ} \mathrm{C}, 1 \mathrm{~min}$ at $60^{\circ} \mathrm{C}$. PCR reaction was performed on an Applied Biosystems 7300 Real-Time PCR system in triplicate and fold changes of the expression were derived using the comparative $\mathrm{C}_{\mathrm{T}}$ method $(42,43)$. Primers used were: human MMP-2-forward, CCCCAGACAGGTGA TCTTGAC and reverse, GCTTGCGAGGGAAGAAGTTG; human MMP-9-forward, CGCTGGGCTTAGATCATTCC and reverse, AGGTTGGATACATCACTGCATTAGG; human GAPDH-forward, ACACCCACTCCTCCACCTTT and reverse, TAGCCAAATTCGTTGTCATACC (40).

Statistical analysis. The student's t-test was used to analyze differences between treated and control groups. $\mathrm{P}<0.05$ was considered to indicate a statistically significant difference $(39,40)$.

\section{Results}

Kaempferol inhibits invasion, migration and adhesion of $U-2$ OS cells. We performed the Matrigel-coated Transwell assay to determine the effects of kaempferol on cell invasion. As shown in Fig. 1A, treatment of U-2 OS cells with increasing concentrations of kaempferol decreased the cell invasion in a concentration-dependent manner. It is possible that kaempferol inhibits migration of U-2 OS cells, leading to the inhibition of cell invasion. To address this possibility, cells were treated with different concentrations of kaempferol for 24 and $48 \mathrm{~h}$ and the effects of kaempferol on cell migration were analyzed by wound-healing assay. As shown in Fig. 1B, cells that migrated into the denuded zones were decreased by kaempferol treatment in a concentration-dependent manner after $24 \mathrm{~h}$ of treatment. We observed the same phenomenon after $48 \mathrm{~h}$ of drug treatment. To examine whether kaempferol also affects cell adhesion, U-2 OS cells were treated with different concentrations of kaempferol and the ability of cells to adhere to extracellular matrix (ECM) was examined by cell-matrix adhesion assay. The result showed that kaempferol treatment inhibited adhesion of cells onto collagen matrix in a concentration-dependent manner, with $>60 \%$ inhibition following treatment with $100 \mu \mathrm{M}$ of kaempferol (Fig. 1C).

Kaempferol reduces the enzymatic activities of $M M P-2$, MMP-9 and UPA of U-2 OS cells. During cancer metastasis, MMPs are produced to degrade ECM, a critical step for cancer invasion. Kaempferol inhibited the enzymatic activities of both MMP-2 and MMP-9 by gelatin zymography 
A
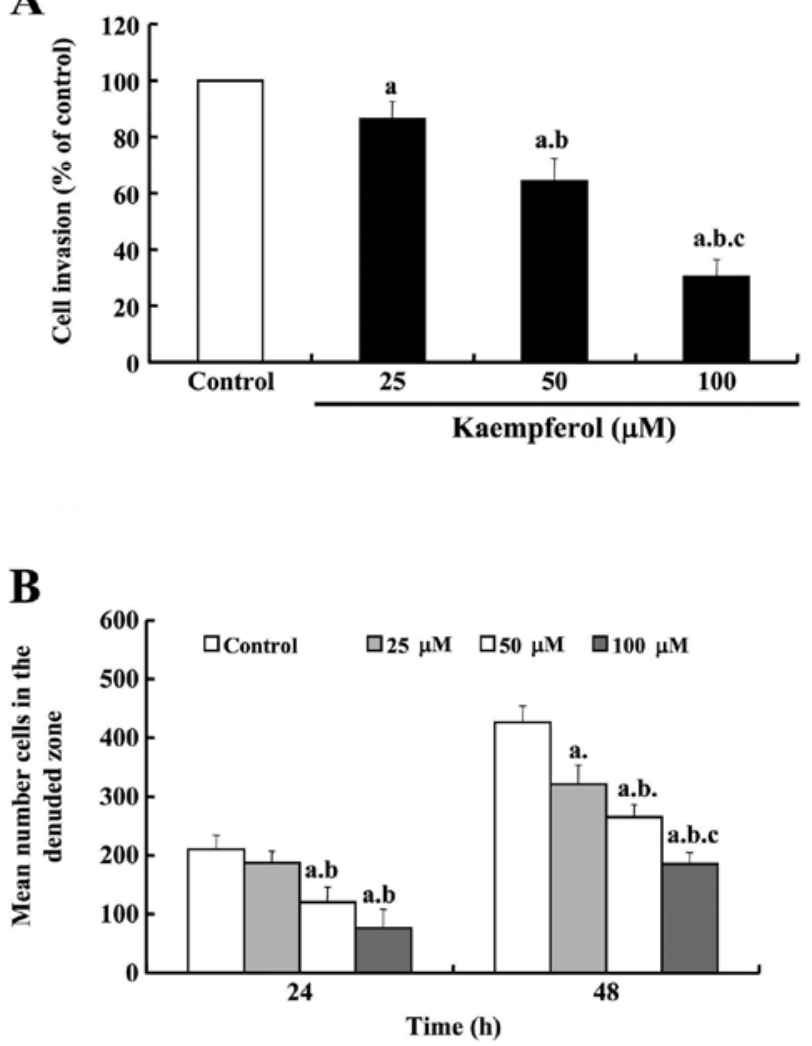

C

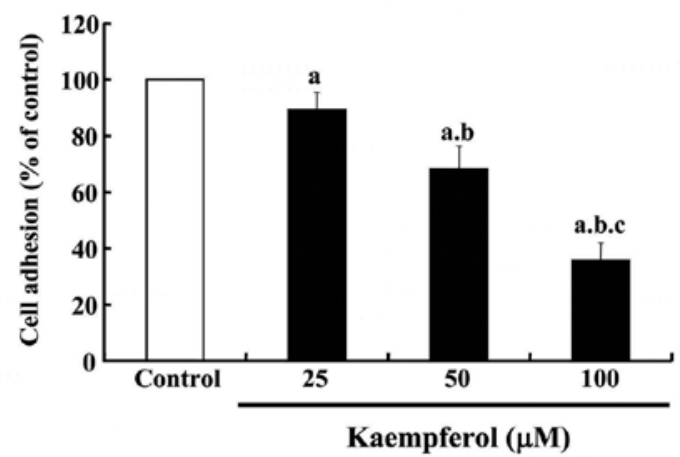

Figure 1. The effects of kaempferol on invasion, migration, and adhesion of U-2 OS cells. (A) Kaempferol inhibits invasion of U-2 OS cells. Cells were treated with kaempferol $(0,25,50$ and $100 \mu \mathrm{M})$ for $48 \mathrm{~h}$ and cells that invaded through Matrigel into the lower surface of the filter were stained and counted. The invaded cells at $0 \mu \mathrm{M}$ of kaempferol (control) were set as $100 \%$, and the relative percentage of invaded cells from other concentrations of kaempferol was calculated accordingly. (B) Kaempferol inhibits migration of U-2 OS cells. Confluent cells were wounded by scratching with a pipette tip and incubated with $(25,50$ and $100 \mu \mathrm{M})$ or without $(0 \mu \mathrm{M})$ kaempferol in serum-free medium for 24 and $48 \mathrm{~h}$. Cells that migrated into the denuded zone were counted and plotted as shown here. (C) Kaempferol reduced adhesion of U-2 OS cells. Cells were treated with kaempferol $(0,25,50$ and $100 \mu \mathrm{M})$ for $48 \mathrm{~h}$ and the cell-matrix assay was performed as described in Materials and methods. The cell adhesion was expressed as percentage by setting control treatment as $100 \%$. Each point is the mean \pm SD of 3 experiments. (a) A significant statistical difference compared to the control. (b) A significant statistical difference compared to the $25 \mu \mathrm{M}$ treatment. (c) A significant statistical difference compared to the $50 \mu \mathrm{M}$ treatment.

analysis (Fig. 2A and B). More than $50 \%$ of enzymatic activity of MMP-2 was inhibited after $50 \mu \mathrm{M}$ of kaempferol treatment. MMP-9 activity was more sensitive to kaempferol than MMP-2, with $>60 \%$ inhibition at $50 \mu \mathrm{M}$ and $>80 \%$ inhibition

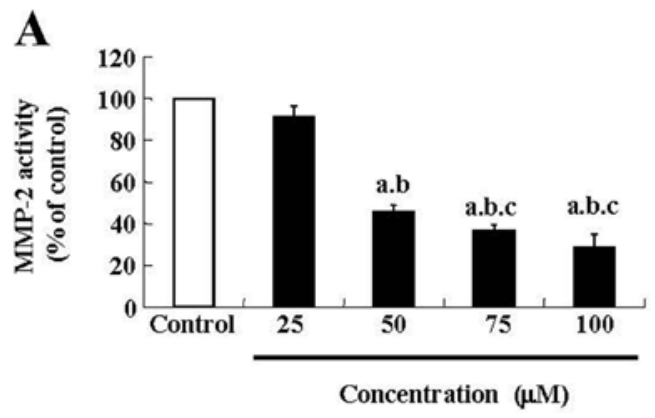

B
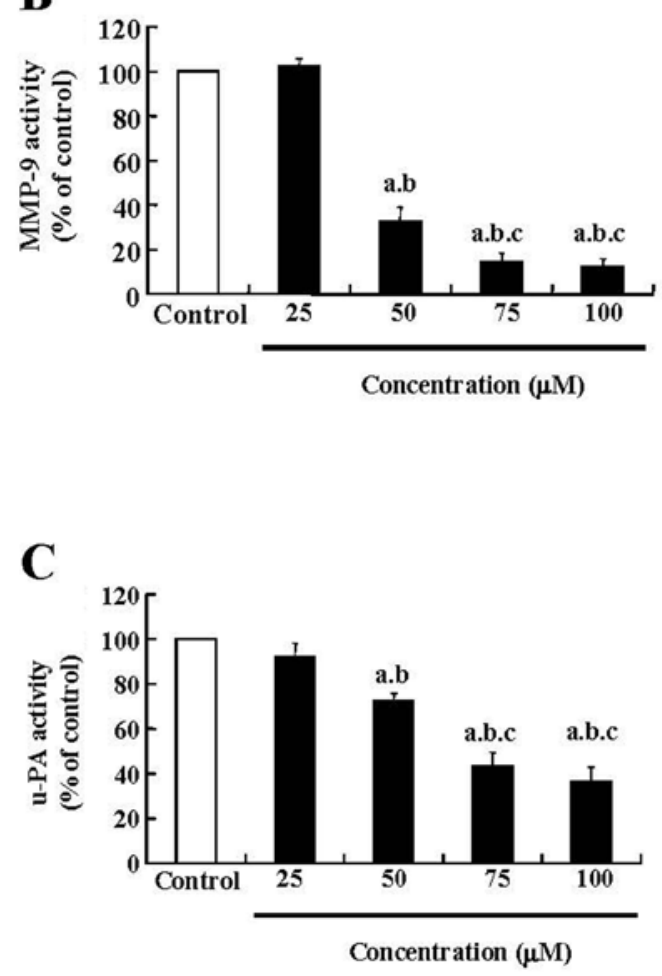

Figure 2. Kaempferol inhibits the enzymatic activities of matrix metalloproteinase (MMP)-2, MMP-9 and urokinase plasminogen activator (uPA) of U-2 OS cells. Cells were treated with different concentrations of kaempferol $(0$, $25,50,75$ and $100 \mu \mathrm{M}$ ) for $48 \mathrm{~h}$. The conditioned media were collected for gelatin or casein zymography assay to determine the (A) MMP-2, (B) MMP-9 and (C) uPA activities. Shown here are the densitometric data expressed as the means \pm SD of 3 independent experiments. Enzymatic activity from control treatment $(0 \mu \mathrm{M})$ was set as $100 \%$ and the percentage of higher drug concentrations was calculated accordingly. (a) A significant statistical difference compared to the control. (b) A significant statistical difference compared to the $25 \mu \mathrm{M}$ treatment. (c) A significant statistical difference compared to the $50 \mu \mathrm{M}$ treatment.

at 75 and $100 \mu \mathrm{M}$. After binding to its cognate receptor on the cell membrane, uPA is activated to convert plasminogen into plasmin, which in turn degrades ECM and cleaves proMMPs, finally leading to cancer metastasis (44). As revealed by casein-plasminogen zymography, kaempferol also reduced the enzymatic activity of uPA, with $>50 \%$ inhibition at drug concentrations $>75 \mu \mathrm{M}$ (Fig. 2C).

Kaempferol reduces the expression of MMP-2, MMP-9 and $u P A$ of $U-2$ OS cells. Since kaempferol reduced the enzymatic 
A

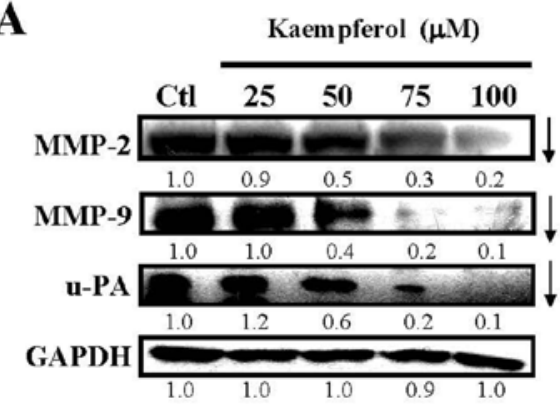

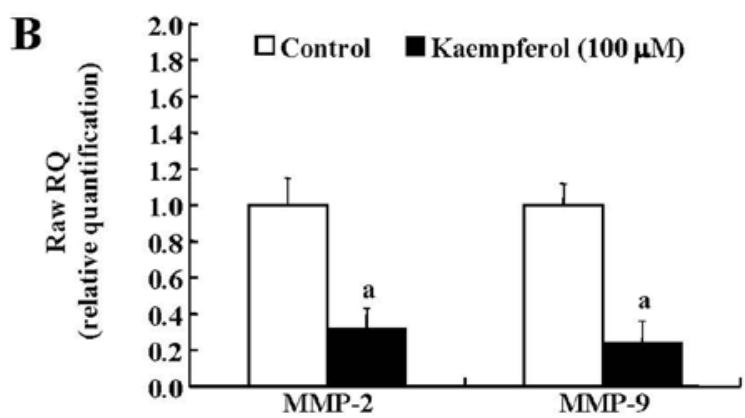

Figure 3. Kaempferol inhibits the expression of matrix metalloproteinases MMP-2, MMP-9 and urokinase plasminogen activator (uPA) of U-2 OS cells. (A) Kaempferol decreases the protein levels of MMP-2, MMP-9 and uPA. Cells were treated with different concentrations of kaempferol (0, 25, 50, 75 and $100 \mu \mathrm{M}$ ) for $48 \mathrm{~h}$. Cells were collected for the preparation of cell lysates and then subjected to western blot analyses for MMP-2, MMP-9 and uPA. GAPDH served as the loading control. (B) Kaempferol decreased the gene expression of MMP-2 and MMP-9. Cells were treated with 0 and $100 \mu$ M of kaempferol for $24 \mathrm{~h}$ and gene expression of MMP-2 and MMP-9 was assessed by quantitative RT-PCR.

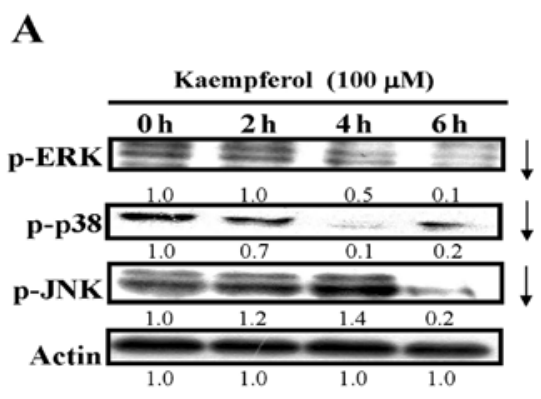

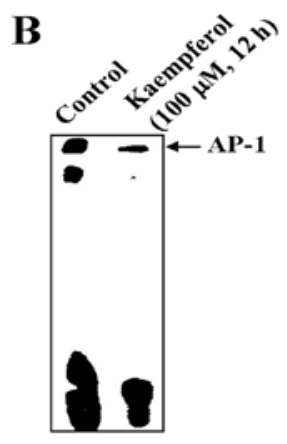

Figure 4. Kaempferol decreases the protein phosphorylation of ERK, p38, JNK and affects the DNA binding activity of AP-1 in U-2 OS cells. (A) Cells were treated with $100 \mu \mathrm{M}$ of kaempferol for different times (0, 2, 4 and $6 \mathrm{~h}$ ) and cells were harvested for western blot analyses with anti-p-ERK, anti-p-p38 and anti-p-JNK antibodies, respectively. (B) Cells were treated with 0 and $100 \mu \mathrm{M}$ of kaempferol for $12 \mathrm{~h}$. Nuclear extracts were obtained to analyze the AP-1 DNA binding activity using biotin end-labeled AP-1 oligonucleotides in electrophoretic mobility-shift assay (EMSA). Lane 1, $0 \mu \mathrm{M}$ of kaempferol (control). Lane 2 , $100 \mu \mathrm{M}$ of kaempferol. The strong signals on the bottom were excessive free probes. Results from 3 independent experiments were comparable.

activities of MMP-2, MMP-9 and uPA, we hypothesized that kaempferol inhibits the expression of MMPs and uPA. Cells were treated with different concentrations of kaempferol for $48 \mathrm{~h}$ and the protein levels of MMP-2, MMP-9 and uPA were examined by western blotting. The result showed that kaempferol treatment decreased the expression of MMP-2, MMP-9 and $\mathrm{uPA}$ at the protein levels in a concentration-dependent manner (Fig. 3A). Approximately $50 \%$ of the protein amount of MMP-2, MMP-9 and uPA was reduced after $50 \mu \mathrm{M}$ of drug treatment and nearly completely diminished after $75 \mu \mathrm{M}$ of kaempferol treatment. To ascertain whether the decrease in the protein levels of MMP-2 and MMP-9 was a result of the decrease in mRNA levels, U-2 OS cells were treated with 0 and $100 \mu \mathrm{M}$ of kaempferol for $24 \mathrm{~h}$, and quantitative RT-PCR analyses of MMP-2 and MMP-9 genes were performed. As compared to control treatment, kaempferol treatment substantially downregulated the mRNA levels of both MMP-2 and MMP-9 genes (Fig. 3B), indicating that the drug acts at the transcriptional level of both genes.

Kaempferol inhibits protein phosphorylation of ERK, p38 and JNK in U-2 OS cells. It has been reported that the MAPK signaling pathway, which includes ERK1/2, C-Jun N-terminal kinase, and p38 kinase pathways, can activate the downstream signaling cascade to increase the expression of MMP family proteins such as MMP-2, MMP-7 and MMP-9, contributing to cancer invasion and metastasis $(45,46)$. We therefore determined the effects of kaempferol on the protein phosphorylation of ERK, JNK and p38. U-2 OS cells were treated with $100 \mu \mathrm{M}$ of kaempferol for 0 to $6 \mathrm{~h}$ and protein phosphorylation was examined by western blot analyses. As shown in Fig. 4A, kaempferol inhibited the protein phosphorylation of ERK, JNK and p38, although the inhibition was in different kinetics for all 3 kinases. Significant inhibition was observed for ERK and p38 after $4 \mathrm{~h}$ of drug treatment, while a longer duration of drug treatment $(6 \mathrm{~h})$ was needed to inhibit the protein phosphorylation of JNK. Our results suggest that kaempferol inhibits protein phosphorylation and, hence, the inactivation of ERK, JNK and p38, contributing to the reduction in the expression and activities of MMPs.

Kaempferol inhibits the DNA binding activity of AP-1 in $U-2$ OS cells. It is known that the promoters of MMP-2, MMP-9 and uPA harbor several consensus binding sites for AP-1 transcription factor (47-49). One possibility is that kaempferol can suppress the DNA binding activity of AP-1, leading to the reduced expression of MMP-2, MMP-9 and uPA. To address this possibility, cells were treated with 0 and $100 \mu \mathrm{M}$ of kaempferol and nuclear extracts were prepared for the EMSA of AP-1 using consensus AP-1 specific oligonucleotides as a 


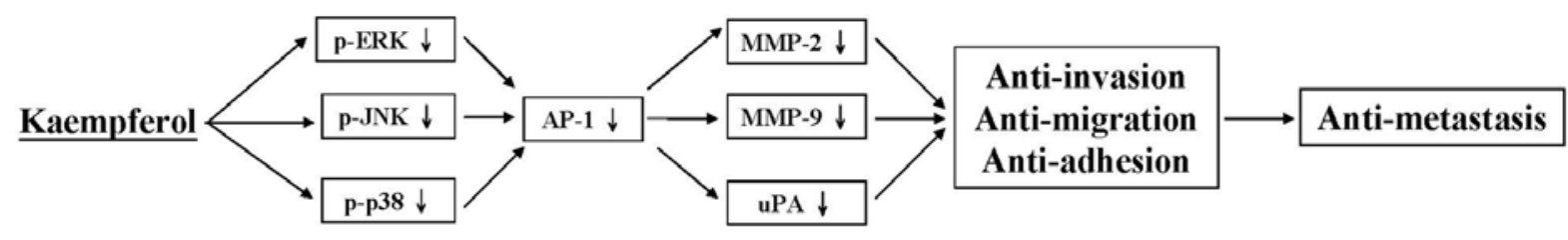

Figure 5. The proposed signaling pathways of kaempferol-inhibited invasion, migration and adhesion in U-2 OS human osteosarcoma cells.

probe. As shown in Fig. 4B, kaempferol treatment inhibited DNA binding activity of AP-1 to its cognate consensus DNA binding motifs. Therefore, our data suggest that kaempferol may inhibit the invasion, migration, and adhesion of U-2 OS cells by attenuating MAPKs/AP-1 -mediated signaling.

\section{Discussion}

Osteosarcoma (OS) is the most frequent primary bone tumor that afflicts children and young adults. It is a highly aggressive tumor that metastasizes primarily to the lungs. Current therapy for the disease involves various combinations of surgery and chemotherapy. The dosage of therapeutic drugs is high, often leading to severe side-effects. Radiotherapy may also be included, but most of the tumors are not sensitive to irradiation. Therefore, there is a pressing need for novel agents for the therapy of the disease, particularly for OS patients with metastatic disease. In the present study, we found that the natural flavonoid, kaempferol, was able to inhibit the invasion, migration and adhesion of U-2 OS cells and could have a potential to treat OS metastasis.

Cancer metastasis is a complicated process that involves the loss of cell adhesion, the increase in cell migration, degradation of extracellular matrix (ECM), invasion of surrounding tissues, intravasation and circulation in the vascular and lymphatic systems, extravasation and finally the dwelling in distant organs (50). Interruption during the earlier steps of metastasis may be more promising for the treatment of cancer metastasis. Our data show that kaempferol can indeed attenuate the metastatic behavior of U-2 OS cells by inhibiting the attachment of cells to the ECM, suppressing cell migration, and blocking the invasion of cells (Fig. 1). The proteolysis of the ECM and basal membranes is a critical step in the invasive processes and the MMPs are responsible for ECM degradation. MMPs are zinc-dependent endopeptidases. According to their structure and substrate specificity, MMPs can be divided into several subgroups including gelatinases, collagenases, stromelysins, membrane-type MMPs and other MMPs (51). The MMP-2/MMP-9 double null mice have defects in tumor angiogenesis and invasion, outlining the importance the gelatinases MMP-2 (gelatinase-A) and MMP-9 (gelatinase-B) in tumor progression (52). Clinically, the expression levels of MMP-2 and MMP-9 in tumors are highly related to the metastatic potential (53-55). Increased expression levels of MMP-2 and MMP-9 were also identified as prognostic markers for a poor outcome of OS (56-58). MMP-9-positive OS patients have an overall 5-year survival rate of $28 \%$, while that of MMP-9-negative OS patients is 79\% (59). Therefore, MMP-2 and MMP-9 are suitable therapeutic targets. In the present study, we found that kaempferol can act on MMP-2 and MMP-9 by decreasing their enzymatic activities and expression at the transcriptional and translational levels (Figs. 2 and 3), leading to the inhibition of invasion of U-2 OS cells. These findings also outline the importance of MMP-2 and MMP-9 in OS metastasis.

Activation of MMPs is initiated by the binding of the uPA to the membrane-bound receptor, the urokinase plasminogen activator receptor (UPAR), and this binding leads to the activation of UPA to convert the plasminogen to plasmin, which in turn cleaves pro-MMPs into active MMPs. Thus, the association of UPA with its cognate receptor UPAR at the surface of cancer cells is considered to be significantly involved in tumor invasion and metastasis $(44,60)$. It has been shown that the uPA-uPAR system plays a critical role in OS metastasis $(61,62)$. In addition, the uPA levels are found to be in an inverse relationship with survival time in OS patients (62). Furthermore, reduction in primary tumor growth and pulmonary metastasis was observed in an in vivo OS model that was inoculated with uPAR antisense clones (63). Based on these observations, inhibition of UPA may be suitable for overcoming OS metastasis. Our results showed that kaempferol not only reduced the enzymatic activity of uPA (Fig. 2C), but also decreased the protein levels of uPA (Fig. 3A), possibly resulting in the inactivation of MMPs and hence the inhibition of invasion of U-2 OS cells.

MAPKs (ERK, p38, JNK) are involved in MMPs or uPA promoter induction through AP-1 $(47,48,64)$ and can regulate the activities of MMPs or uPA in various cell types (65-67). AP-1 is comprised of Fos and Jun proteins and functions as a transcription factor that controls cell proliferation, differentiation, and bone metabolism. Studies have shown that Fos and Jun are significantly upregulated in high-grade OS, as compared to benign osteoblastic lesions and low-grade OS $(68,69)$ and tend to develop metastases (70). It was reported that inhibition of AP-1-mediated transcription resulted in reduced migration, invasion and metastasis in a murine model of OS $(71,72)$. These data strongly suggest that MAPKs and AP-1 function as mediators of cancer metastasis and our current study indicated that kaempferol can inhibit the metastasis of OS cells by suppressing the activation of these two important mediators.

In summary, the inhibitory effects of kaempferol on the metastasis of OS are delineated in Fig. 5. The natural flavonoid kaempferol exhibits anti-metastasis activity by blocking the activation of MAPKs and AP-1 signaling pathways to reduce the expression and activities of MMPs and UPA and results in the inhibition of invasion, migration and adhesion of OS cells. Our previous studies have shown that kaempferol reduced the cell viability, induced cell apoptosis of U-2 OS cells and inhibited tumor growth in BALB/c $/ \mathrm{c}^{\text {nu/nu }}$ mice inoculated with U-2 OS cells, but exhibited low cytotoxicity on human fetal osteoblast progenitor (hFOB) cells (34). In the present study, we further demonstrated that kaempferol inhibited the meta- 
static potential including invasion, migration and adhesion of U-2 OS cells. Due to its relative non-toxic, inexpensive nature and its ability to suppress cell growth and inhibit the metastatic potential of OS, kaempferol is a promising agent for the therapy of OS and metastasis of the disease.

\section{Acknowledgements}

This study was supported in part by research grants from the National Science Council of the Republic of China (NSC 101-2313-B-039-008) awarded to J.S. Yang.

\section{References}

1. Kansara M and Thomas DM: Molecular pathogenesis of osteosarcoma. DNA Cell Biol 26: 1-18, 2007.

2. Ottaviani G and Jaffe N: The epidemiology of osteosarcoma. Cancer Treat Res 152: 3-13, 2009.

3. Whelan JS: Osteosarcoma. Eur J Cancer 33: 1611-1618, 1997.

4. Krishnan K, Khanna C and Helman LJ: The biology of metastases in pediatric sarcomas. Cancer J 11: 306-313, 2005.

5. Hayden JB and Hoang BH: Osteosarcoma: basic science and clinical implications. Orthop Clin North Am 37: 1-7, 2006.

6. Meyers PA, Schwartz CL, Krailo M, et al: Osteosarcoma: a randomized, prospective trial of the addition of ifosfamide and/or muramyl tripeptide to cisplatin, doxorubicin, and high-dose methotrexate. J Clin Oncol 23: 2004-2011, 2005.

7. Meyers PA: Muramyl tripeptide (mifamurtide) for the treatment of osteosarcoma. Expert Rev Anticancer Ther 9: 1035-1049, 2009.

8. Hodek P, Trefil P and Stiborová M: Flavonoids-potent and versatile biologically active compounds interacting with cytochromes P450. Chem Biol Interact 139: 1-21, 2002.

9. Pietta PG: Flavonoids as antioxidants. J Nat Prod 63: 1035-1042, 2000.

10. Weng CJ and Yen GC: Flavonoids, a ubiquitous dietary phenolic subclass, exert extensive in vitro anti-invasive and in vivo antimetastatic activities. Cancer Metastasis Rev 31: 323-351, 2012.

11. Middleton E Jr, Kandaswami C and Theoharides TC: The effects of plant flavonoids on mammalian cells: implications for inflammation, heart disease, and cancer. Pharmacol Rev 52: 673-751, 2000.

12. Guo Q, Zhao L, You Q, et al: Anti-hepatitis B virus activity of wogonin in vitro and in vivo. Antiviral Res 74: 16-24, 2007.

13. Cárdenas M, Marder M, Blank VC and Roguin LP: Antitumor activity of some natural flavonoids and synthetic derivatives on various human and murine cancer cell lines. Bioorg Med Chem 14: 2966-2971, 2006.

14. Burda S and Oleszek W: Antioxidant and antiradical activities of flavonoids. J Agric Food Chem 49: 2774-2779, 2001.

15. Crespo I, García-Mediavilla MV, Gutiérrez B, Sánchez-Campos S, Tuñón MJ and González-Gallego J: A comparison of the effects of kaempferol and quercetin on cytokine-induced pro-inflammatory status of cultured human endothelial cells. Br J Nutr 100: 968-976, 2008.

16. Yamamoto Y and Gaynor RB: Therapeutic potential of inhibition of the NF- $\kappa$ B pathway in the treatment of inflammation and cancer. J Clin Invest 107: 135-142, 2001.

17. Cushnie TP and Lamb AJ: Antimicrobial activity of flavonoids. Int J Antimicrob Agents 26: 343-356, 2005.

18. Yu SF, Shun CT, Chen TM and Chen YH: 3-O- $\beta$-D-glucosyl$(1 \rightarrow 6)-\beta-D$-glucosyl-kaempferol isolated from Sauropus androgenus reduces body weight gain in Wistar rats. Biol Pharm Bull 29: 2510-2513, 2006.

19. Yao P, Nussler A, Liu L, et al: Quercetin protects human hepatocytes from ethanol-derived oxidative stress by inducing heme oxygenase-1 via the MAPK/Nrf2 pathways. J Hepatol 47: 253-261, 2007.

20. Tijburg LB, Mattern T, Folts JD, Weisgerber UM and Katan MB: Tea flavonoids and cardiovascular disease: a review. Crit Rev Food Sci Nutr 37: 771-785, 1997.

21. Park JS, Rho HS, Kim DH and Chang IS: Enzymatic preparation of kaempferol from green tea seed and its antioxidant activity. J Agric Food Chem 54: 2951-2956, 2006.

22. Stewart AJ, Bozonnet S, Mullen W, Jenkins GI, Lean ME and Crozier A: Occurrence of flavonols in tomatoes and tomatobased products. J Agric Food Chem 48: 2663-2669, 2000.
23. Jaganathan SK and Mandal M: Antiproliferative effects of honey and of its polyphenols: a review. J Biomed Biotechnol 2009: 830616, 2009.

24. Zhang Y, Seeram NP, Lee R, Feng L and Heber D: Isolation and identification of strawberry phenolics with antioxidant and human cancer cell antiproliferative properties. J Agric Food Chem 56: 670-675, 2008.

25. Kang JW, Kim JH, Song K, Kim SH, Yoon JH and Kim KS: Kaempferol and quercetin, components of Ginkgo biloba extract (EGb 761), induce caspase-3-dependent apoptosis in oral cavity cancer cells. Phytother Res 24 (Suppl 1): S77-S82, 2010.

26. Bajpai M, Pande A, Tewari SK and Prakash D: Phenolic contents and antioxidant activity of some food and medicinal plants. Int J Food Sci Nutr 56: 287-291, 2005.

27. Calderón-Montaño JM, Burgos-Morón E, Pérez-Guerrero $\mathrm{C}$ and López-Lázaro M: A review on the dietary flavonoid kaempferol. Mini Rev Med Chem 11: 298-344, 2011

28. Leung HW, Lin CJ, Hour MJ, Yang WH, Wang MY and Lee HZ: Kaempferol induces apoptosis in human lung non-small carcinoma cells accompanied by an induction of antioxidant enzymes. Food Chem Toxicol 45: 2005-2013, 2007.

29. Zhang Q, Zhao XH and Wang ZJ: Flavones and flavonols exert cytotoxic effects on a human oesophageal adenocarcinoma cell line (OE33) by causing $\mathrm{G} 2 / \mathrm{M}$ arrest and inducing apoptosis. Food Chem Toxicol 46: 2042-2053, 2008.

30. Marfe G, Tafani M, Indelicato M, et al: Kaempferol induces apoptosis in two different cell lines via Akt inactivation, Bax and SIRT3 activation, and mitochondrial dysfunction. J Cell Biochem 106: 643-650, 2009.

31. Kim KS, Rhee KH, Yoon JH, Lee JG, Lee JH and Yoo JB: Ginkgo biloba extract (EGb 761) induces apoptosis by the activation of caspase-3 in oral cavity cancer cells. Oral Oncol 41: 383-389, 2005.

32. De Leo M, Braca A, Sanogo R, Cardile V, DeTommasi N and Russo A: Antiproliferative activity of Pteleopsis suberosa leaf extract and its flavonoid components in human prostate carcinoma cells. Planta Med 72: 604-610, 2006.

33. Mutoh M, Takahashi M, Fukuda K, et al: Suppression of cyclooxygenase- 2 promoter-dependent transcriptional activity in colon cancer cells by chemopreventive agents with a resorcintype structure. Carcinogenesis 21: 959-963, 2000.

34. Huang WW, Chiu YJ, Fan MJ, et al: Kaempferol induced apoptosis via endoplasmic reticulum stress and mitochondriadependent pathway in human osteosarcoma U-2 OS cells. Mol Nutr Food Res 54: 1585-1595, 2010.

35. Sliva D: Suppression of cancer invasiveness by dietary compounds. Mini Rev Med Chem 8: 677-688, 2008.

36. Phromnoi K, Yodkeeree S, Anuchapreeda S and Limtrakul P: Inhibition of MMP-3 activity and invasion of the MDA-MB-231 human invasive breast carcinoma cell line by bioflavonoids. Acta Pharmacol Sin 30: 1169-1176, 2009.

37. Labbé D, Provençal M, Lamy S, Boivin D, Gingras D and Béliveau R: The flavonols quercetin, kaempferol, and myricetin inhibit hepatocyte growth factor-induced medulloblastoma cell migration. J Nutr 139: 646-652, 2009.

38. Lin CW, Shen SC, Chien CC, Yang LY, Shia LT and Chen YC: 12- $O$-tetradecanoylphorbol-13-acetate-induced invasion/migration of glioblastoma cells through activating PKC $\alpha /$ ERK/NF- $\kappa \mathrm{B}$-dependent MMP-9 expression. J Cell Physiol 225: 472-481, 2010.

39. Chiu YJ, Hour MJ, Lu CC, et al: Novel quinazoline HMJ-30 induces U-2 OS human osteogenic sarcoma cell apoptosis through induction of oxidative stress and up-regulation of ATM/p53 signaling pathway. J Orthop Res 29: 1448-1456, 2011.

40. Chen KT, Hour MJ, Tsai SC, et al: The novel synthesized 6-fluoro(3-fluorophenyl)-4-(3-methoxyanilino)quinazoline (LJJ-10) compound exhibits anti-metastatic effects in human osteosarcoma U-2 OS cells through targeting insulin-like growth factor-I receptor. Int J Oncol 39: 611-619, 2011.

41. Hour MJ, Tsai SC, Wu HC, et al: Antitumor effects of the novel quinazolinone MJ-33: Inhibition of metastasis through the MAPK, AKT, NF- $\kappa$ B and AP-1 signaling pathways in DU145 human prostate cancer cells. Int J Oncol 41: 1513-1519, 2012.

42. Lai KC, Huang AC, Hsu SC, et al: Benzyl isothiocyanate (BITC) inhibits migration and invasion of human colon cancer HT29 cells by inhibiting matrix metalloproteinase-2/-9 and urokinase plasminogen (uPA) through PKC and MAPK signaling pathway. J Agric Food Chem 58: 2935-2942, 2010. 
43. Kao WT, Lin CY, Lee LT, et al: Investigation of MMP-2 and -9 in a highly invasive A431 tumor cell sub-line selected from a Boyden chamber assay. Anticancer Res 28: 2109-2120, 2008.

44. Mazar AP: The urokinase plasminogen activator receptor (uPAR) as a target for the diagnosis and therapy of cancer. Anticancer Drugs 12: 387-400, 2001.

45. Kawabata K, Murakami A and Ohigashi H: Citrus auraptene targets translation of MMP-7 (matrilysin) via ERK1/2-dependent and mTOR-independent mechanism. FEBS Lett 580: 5288-5294, 2006.

46. Mook OR, Frederiks WM and Van Noorden CJ: The role of gelatinases in colorectal cancer progression and metastasis. Biochim Biophys Acta 1705: 69-89, 2004

47. Ried S, Jäger C, Jeffers M, et al: Activation mechanisms of the urokinase-type plasminogen activator promoter by hepatocyte growth factor/scatter factor. J Biol Chem 274: 16377-16386, 1999.

48. Lengyel E, Stepp E, Gum R and Boyd D: Involvement of a mitogen-activated protein kinase signaling pathway in the regulation of urokinase promoter activity by c-Ha-ras. J Biol Chem 270: 23007-23012, 1995.

49. Peng PL, Hsieh YS, Wang CJ, Hsu JL and Chou FP: Inhibitory effect of berberine on the invasion of human lung cancer cells via decreased productions of urokinase-plasminogen activator and matrix metalloproteinase-2. Toxicol Appl Pharmacol 214: 8-15, 2006.

50. Hanahan D and Weinberg RA: The hallmarks of cancer. Cell 100: 57-70, 2000.

51. Denys H, De Wever O, Nusgens B, et al: Invasion and MMP expression profile in desmoid tumours. Br J Cancer 90: 1443-1449, 2004.

52. Masson V, de la Ballina LR, Munaut C, et al: Contribution of host MMP-2 and MMP-9 to promote tumor vascularization and invasion of malignant keratinocytes. FASEB J 19: 234-236, 2005.

53. Duffy MJ, Maguire TM, Hill A, McDermott E and O'Higgins N: Metalloproteinases: role in breast carcinogenesis, invasion and metastasis. Breast Cancer Res 2: 252-257, 2000.

54. Hanemaaijer R, Verheijen JH, Maguire TM, et al: Increased gelatinase-A and gelatinase-B activities in malignant vs. benign breast tumors. Int J Cancer 86: 204-207, 2000.

55. Chambers AF and Matrisian LM: Changing views of the role of matrix metalloproteinases in metastasis. J Natl Cancer Inst 89 1260-1270, 1997.

56. Ferrari C, Benassi S, Ponticelli F, et al: Role of MMP-9 and its tissue inhibitor TIMP-1 in human osteosarcoma: findings in 42 patients followed for 1-16 years. Acta Orthop Scand 75 487-491, 2004

57. Bjornland K, Flatmark K, Pettersen S, Aaasen AO, Fodstad O and Maelandsmo GM: Matrix metalloproteinases participate in osteosarcoma invasion. J Surg Res 127: 151-156, 2005.
58. Uchibori M, Nishida Y, Nagasaka T, Yamada Y, Nakanishi K and Ishiguro $\mathrm{N}$ : Increased expression of membrane-type matrix metalloproteinase-1 is correlated with poor prognosis in patients with osteosarcoma. Int J Oncol 28: 33-42, 2006.

59. Foukas AF, Deshmukh NS, Grimer RJ, Mangham DC, Mangos EG and Taylor S: Stage-IIB osteosarcomas around the knee. A study of MMP-9 in surviving tumour cells. J Bone Joint Surg Br 84: 706-711, 2002.

60. Sliva D, English D, Lyons D and Lloyd FP Jr: Protein kinase C induces motility of breast cancers by upregulating secretion of urokinase-type plasminogen activator through activation of AP-1 and NF- $\kappa$ B. Biochem Biophys Res Commun 290: 552-557, 2002.

61. Choong PF and Nadesapillai AP: Urokinase plasminogen activator system: a multifunctional role in tumor progression and metastasis. Clin Orthop Relat Res (Suppl 415): S46-S58, 2003.

62. Choong PF, Fernö M, Akerman M, et al: Urokinase-plasminogenactivator levels and prognosis in 69 soft-tissue sarcomas. Int J Cancer 69: 268-272, 1996.

63. Dass CR, Nadesapillai AP, Robin D, et al: Downregulation of uPAR confirms link in growth and metastasis of osteosarcoma. Clin Exp Metastasis 22: 643-652, 2005.

64. Gondi CS and Rao JS: Therapeutic potential of siRNA-mediated targeting of urokinase plasminogen activator, its receptor, and matrix metalloproteinases. Methods Mol Biol 487: 267-281, 2009.

65. Chen PN, Hsieh YS, Chiou HL and Chu SC: Silibinin inhibits cell invasion through inactivation of both PI3K-Akt and MAPK signaling pathways. Chem Biol Interact 156: 141-150, 2005.

66. Westermarck J and Kähäri VM: Regulation of matrix metalloproteinase expression in tumor invasion. FASEB J 13: 781-792, 1999.

67. Aguirre Ghiso JA, Alonso DF, Farías EF, Gomez DE and de Kier Joffè EB: Deregulation of the signaling pathways controlling urokinase production. Its relationship with the invasive phenotype. Eur J Biochem 263: 295-304, 1999.

68. Wu JX, Carpenter PM, Gresens C, et al: The proto-oncogene c-fos is over-expressed in the majority of human osteosarcomas. Oncogene 5: 989-1000, 1990

69. Franchi A, Calzolari A and Zampi G: Immunohistochemical detection of c-fos and c-jun expression in osseous and cartilaginous tumours of the skeleton. Virchows Arch 432: 515-519, 1998.

70. Gamberi G, Benassi MS, Bohling T, et al: C-myc and c-fos in human osteosarcoma: prognostic value of mRNA and protein expression. Oncology 55: 556-563, 1998

71. Leaner VD, Chick JF, Donninger H, et al: Inhibition of AP-1 transcriptional activity blocks the migration, invasion, and experimental metastasis of murine osteosarcoma. Am J Pathol 174: 265-275, 2009

72. Tan ML, Choong PF and Dass CR: Direct anti-metastatic efficacy by the DNA enzyme Dz13 and downregulated MMP-2, MMP-9 and MT1-MMP in tumours. Cancer Cell Int 10: 9, 2010. 